\title{
Birth weight centiles by gestational age for twins born in south India
}

\author{
Prasanna Premkumar ${ }^{*}$, Belavendra Antonisamy, Jiji Mathews², Santhosh Benjamin², Annie Regi ${ }^{2}$, Ruby Jose², \\ Anil Kuruvilla ${ }^{3}$ and Mathews Mathai ${ }^{4}$
}

\begin{abstract}
Background: Birth weight centile curves are commonly used as a screening tool and to assess the position of a newborn on a given reference distribution. Birth weight of twins are known to be less than those of comparable singletons and twin-specific birth weight centile curves are recommended for use. In this study, we aim to construct gestational age specific birth weight centile curves for twins born in south India.

Methods: The study was conducted at the Christian Medical College, Vellore, south India. The birth records of all consecutive pregnancies resulting in twin births between 1991 and 2005 were reviewed. Only live twin births between 24 and 42 weeks of gestation were included. Birth weight centiles for gestational age were obtained using the methodology of generalized additive models for location, scale and shape (GAMLSS). Centiles curves were obtained separately for monochorionic and dichorionic twins.

Results: Of 1530 twin pregnancies delivered during the study period (1991-2005), 1304 were included in the analysis. The median gestational age at birth was 36 weeks (1st quartile 34, 3rd quartile 38 weeks). Smoothed percentile curves for birth weight by gestational age increased progressively till 38 weeks and levels off thereafter. Compared with dichorionic twins, monochorionic twins had lower birth weight for gestational age from after 27 weeks.
\end{abstract}

Conclusions: We provide centile values of birth weight at 24 to 42 completed weeks of gestation for twins born in south India. These charts could be used both in routine clinical assessments and epidemiological studies.

Keywords: Twins, Birth weight, Gestational age, Centiles, India, GAMLSS

\section{Background}

Rate of twin births is rising due to the increased use of assisted reproductive technologies in the recent years [1]. Birth weight of twins are considerably lower than singletons and associated with higher risk for adverse perinatal and infant outcomes [2, 3]. Birth weight centiles by gestational age is often used as a health indicator and to understand the natural extent of variation in birth weight. There have been many studies of twin birth weight centiles worldwide [4-7], but are of limited use in developing settings like India owing to the use of non-representative populations. In India, information on twins is quite limited, and most previous studies on centile curves focused only on singleton births [8-10].

\footnotetext{
* Correspondence: prasanna.samuel@cmcvellore.ac.in

${ }^{1}$ Departments of Biostatistics, Christian Medical College, Vellore 632 002, India Full list of author information is available at the end of the article
}

Currently, the clinical practice is that centiles curves for singleton births are used as an estimate to evaluate twin births. However, recent studies suggest use of singleton centile curves on twins is not appropriate as twins experience different growth trajectories than singletons [11]. Moreover, several studies have recommended the development of twin specific centile curves to evaluate twin births [12-15].

Twin births are further complicated by placental chorionicity. Monochorionic twins present a two to three times higher risk for adverse outcomes than dichorionic twins [16], with birth weights of monochorionic twins lower than those of dichorionic twins over the gestational ages. Further, monochorionic placentation increases the risk of serious pregnancy complications (such as twin-to-twin transfusion syndrome), congenital anomalies, growth restriction, and perinatal death [17]. 
Past studies have indicated that placental chorionicity should be taken into consideration in assessment of twin births [18]. The lack of centile curves specific to twins could be a limiting factor in understanding the distribution of birth weight and further evaluation of twin births. Therefore, we carried out the present study to construct gestational age specific birth weight centile curves for twins born in South India, stratified by placental chorionicity (monochorionic and dichorionic placentation).

\section{Methods}

\section{Setting and population}

This study was based on labour room records and medical records maintained by the Department of Obstetrics and Gynaecology at the Christian Medical College, Vellore. This hospital serves as a maternity centre with almost 9000 deliveries annually (during the study period, 1991-2005). It provides obstetric care to local population of Vellore city and for surrounding towns and villages and also acts as a tertiary hospital. Besides women from Vellore district, women from neighbouring districts in Tamil Nadu and adjoining states of Andhra Pradesh and Karnataka also deliver in the institution. Most pregnancies are registered early during the first or second trimesters and followed up thereafter for antenatal care.

Ethical approval of the study protocol was obtained from the Institutional Review Board (IRB: 2000-no.4481) of the Christian Medical College, Vellore. However, because of the retrospective nature of the study and data were extracted from medical records/labour room registers with no individual identifications, and hence individual informed consent was not obtained.

\section{Study sample}

The study sample included all twin pregnancies delivered at the centre between January 1, 1991 and December 31, 2005. Pregnancies in which at least one child died, or missing information on study variables were excluded from further analysis.

\section{Study variables}

Birth weight was measured immediately after birth on a Braun weighing scale to the nearest $50 \mathrm{~g}$. Gestational age was determined as the number of completed weeks of gestation from the last menstrual period (LMP) to the date of birth. This was best estimated using combinations of the last menstrual period (LMP), early clinical examination and early ultrasound scans. If there was a difference between gestational age estimated from LMP and ultrasound, the ultrasound estimate was used. Placental chorionicity was diagnosed by ultrasound and confirmed by gross examination of placenta after the birth.

\section{Statistical analysis}

From an initial exploratory analysis, we found that the distribution of birth weight at extreme gestational ages was non-normal and the general pattern of relationship between birth weight and gestational age was not linear. Given these violations in the usual assumptions of regression analyses, we chose the generalized additive model for location scale and shape (GAMLSS) approach [19]. This approach is highly flexible as it relaxes the traditional distributional assumptions about normality to include even highly skewed and kurtotic distributions. It extends not only to model mean but all other parameters (standard deviation, skewness and kurtosis) of the distribution as linear, non linear or smoothing functions of explanatory variables (gestational age). In our analyses, we have used Box-Cox t (BCT) distribution for modeling birth weight as non-parametric cubic spline functions of gestational age. Model selection was based on generalized Akaike Information Criterion (GAIC) and the model with smallest value of the GAIC is selected. Worm plots were used for visual inspection of the fit of the smoothed curves and were further confirmed by superimposing the smoothed centiles on observed empirical centiles. Centile curves were obtained for the entire sample and were also constructed according to placental chorionicity. The GAMLSS package for $\mathrm{R}$ statistical software (version 2.13.1) was used for the analysis [20].

\section{Results}

During the study period, a total of 1673 multiple pregnancies were delivered. Of which, the following were removed sequentially from further analysis (triplets $=39$; fetal deaths of one or more foetuses $=141$; missing data on chorionicity $=170$; and missing data on birth weight and/or gestational age $=19$ ). Thus complete data were available from 1304 twin gestations for analyses. The mean maternal age of mothers included in the sample was 25.2 years $(\mathrm{SD}=4.3)$ and $46 \%$ of mothers were primigravid. A total of $88(6.7 \%)$ mothers were conceived using some form of assisted reproductive technologies, while approximately (64) $5 \%$ of mothers experienced gestational diabetes and (224) $17 \%$ had preeclampsia. Eighty two percent of the women in our sample were Hindus, $11 \%$ were Muslims and $7 \%$ were Christians. About $8 \%$ (106) of mothers were illiterates. There were 457 (35\%) monochorionic pregnancies.

The median gestational age at birth was 36 weeks (IQR 34-38 weeks). There was a $4.1 \%$ increase in adjusted (for gestational age) mean birth weight from $2050 \mathrm{~g}$ in 1991 to 2135 in 2005. Dichorionic twins were heavier than monochorionic twins with an adjusted (for gestational age) mean of $2138 \mathrm{~g}$ compared with 2, $054 \mathrm{~g}$ respectively. The mean birth weight discordance was 
$13.1 \%(\mathrm{SD}=10.3 \%$, median $=11.1 \%)$. Considering a threshold of $18 \%$ [18], birth weight discordance was identified in 360 out of 1304 pregnancies (27.6\%).

Examining the 50th centile, the weekly increase in birth weight flattens by 38 weeks of gestation and thereafter gain in the median birth weight was negligible (Fig. 1). To assess the validity of the fitted model, the expected percentage of observed birth weights below each centile was compared with observed percentage across gestational ages. About, $9 \%$ fell below the 10th centile, $80.4 \%$ between 10th and 90th centile and $9.9 \%$ above the 90th centile. Further, the fit of the curves estimated from the statistical models were confirmed by overlaying the empirical centiles on top of the smoothed centiles (Fig. 1).

Figure 2 present birth weight centile curves for twins according to placental chorionicity. Monochorionic twins were consistently smaller than dichorionic twins after 27 weeks of gestation, with a fall-off across centiles of birthweight (Tables 1 and 2).

\section{Discussion}

In this study, we constructed new birth weight centile curves for twins born in South India. We have presented centile curves by chorionic placentation to facilitate consideration of chorionicity in the assessment of twin births.
The overall pattern of change in birthweight over gestational age was characterized by a rapid change in weight till 38 weeks and reduction in change then onwards. Given that it is increasingly possible to determine chorionicity prenatally, it is important to consider placental chorionicity in the assessment of growth in twins. Our comparison of centile curves by chorionicity showed that birth weights of monochorionic twins were lower than dichorionic twins in gestational ages between 28 and 42 weeks. This could be explained by the increased demands with advancing gestational age in monochorionic twins which share a common placenta and this heightened demand may not be met as adequately as in dichorionic twins- leading to the difference between two groups.

Previous studies on distribution of birth weights in India have mainly been based on singleton births. Birth weights from our study were consistently lower than those of singletons [8]; the differences were approximately 500 g between gestational ages 32 and 42 weeks. This difference was similar to that seen in other published studies on the birth weight centile curves for twins $[4,6]$.

The data presented here is based on the largest sample size reported till date from India. However, in developing settings like India, it is considerably difficult to obtain precise obstetrical records on measurements at birth for a large number of twins, as there are not many population

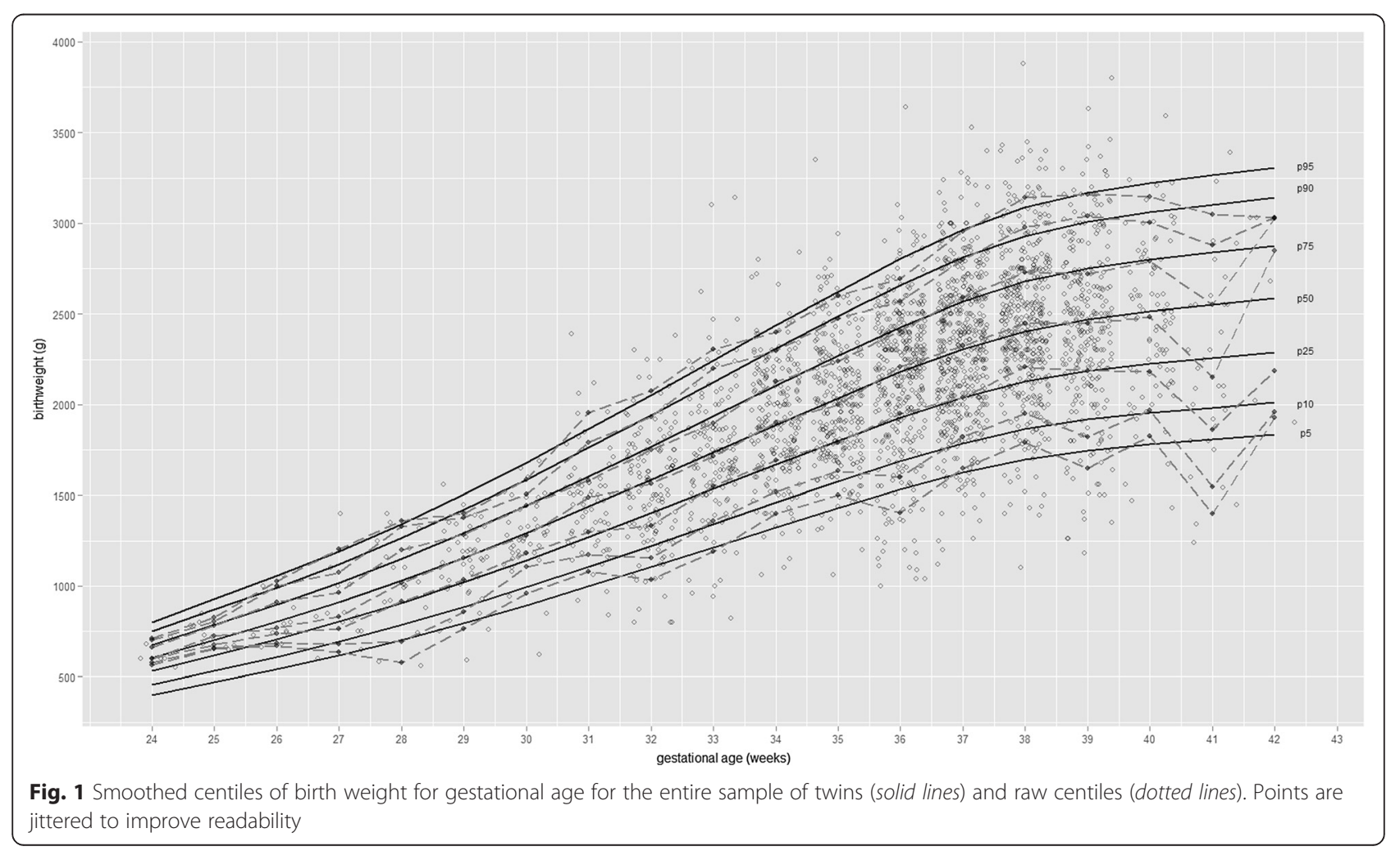




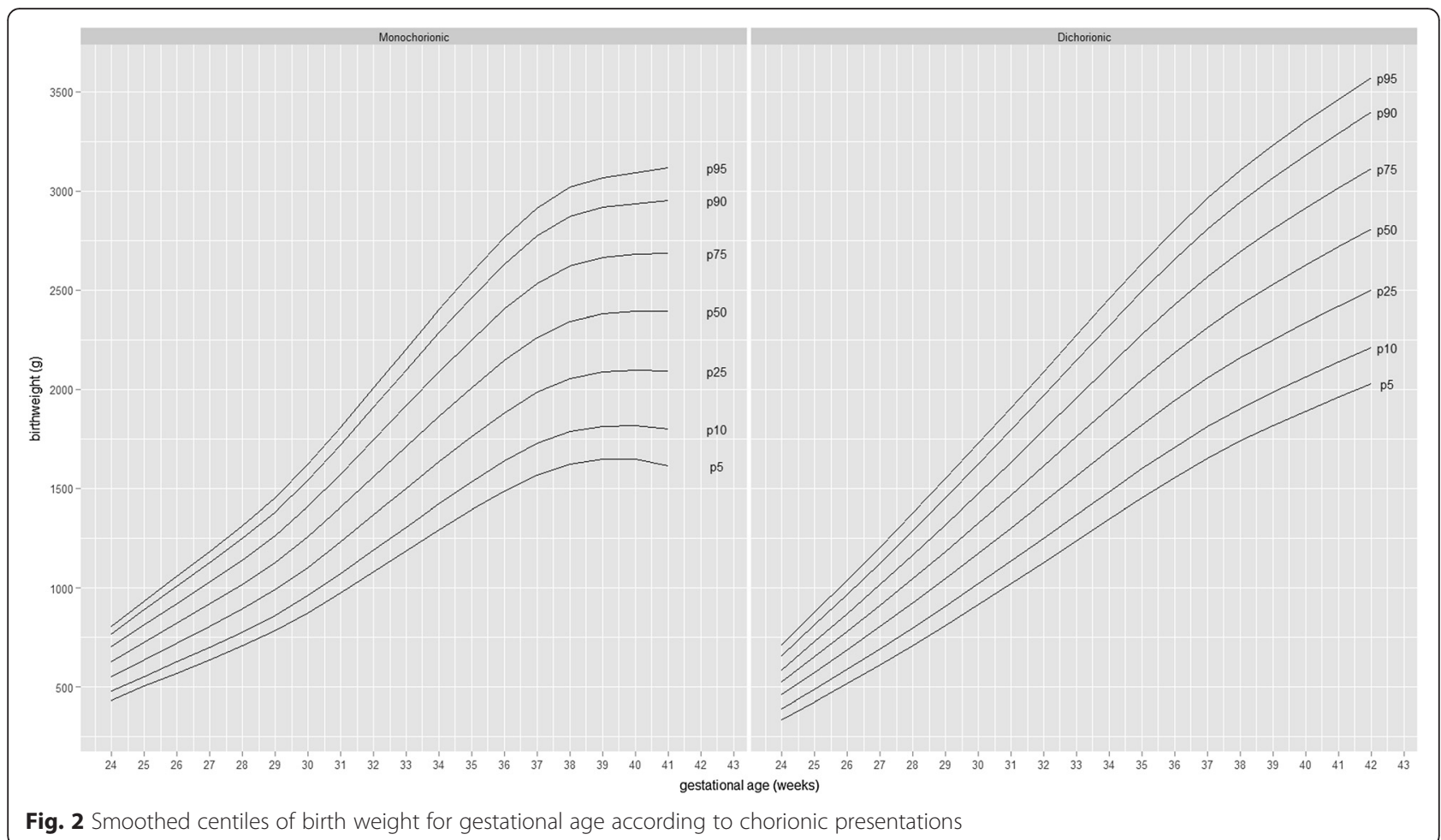

Table 1 Distribution of birthweight by gestational age (weeks) for twins according to chorionic placentation

\begin{tabular}{|c|c|c|c|c|c|c|c|c|c|c|c|c|}
\hline \multirow[b]{2}{*}{ GA } & \multicolumn{6}{|c|}{ Monochorionic } & \multicolumn{6}{|c|}{ Dichorionic } \\
\hline & $\mathrm{N}$ & P10 & P50 & P90 & Mean & SD & $\mathrm{N}$ & P10 & P50 & P90 & Mean & SD \\
\hline 24 & 4 & 600 & 640 & 708 & 650 & 60.00 & 2 & 555 & 575 & 595 & 575 & 35.36 \\
\hline 25 & 8 & 657 & 725 & 815 & 733.75 & 71.30 & 2 & 681 & 725 & 769 & 725 & 77.78 \\
\hline 26 & 8 & 709 & 840 & 1018 & 860 & 147.45 & 4 & 698 & 740 & 775 & 737.5 & 45.00 \\
\hline 27 & 2 & 756 & 780 & 804 & 780 & 42.43 & 12 & 660 & 840 & 1091 & 889.17 & 215.43 \\
\hline 28 & 6 & 830 & 1120 & 1375 & 1108.33 & 264.08 & 12 & 610 & 1015 & 1205 & 987.5 & 230.26 \\
\hline 29 & 26 & 785 & 1125 & 1300 & 1076.92 & 195.44 & 16 & 1060 & 1265 & 1425 & 1243.75 & 176.74 \\
\hline 30 & 18 & 1052 & 1270 & 1503 & 1263.89 & 182.92 & 26 & 1130 & 1285 & 1550 & 1304.23 & 220.53 \\
\hline 31 & 18 & 1075 & 1400 & 1645 & 1387.22 & 275.66 & 50 & 1189 & 1500 & 1823 & 1504.2 & 275.19 \\
\hline 32 & 54 & 1212 & 1550 & 1947 & 1578.89 & 306.84 & 80 & 1104 & 1580 & 1873 & 1531.62 & 322.79 \\
\hline 33 & 54 & 1258 & 1680 & 1887 & 1633.7 & 303.12 & 84 & 1383 & 1750 & 2278 & 1820.82 & 380.85 \\
\hline 34 & 70 & 1489 & 1922.5 & 2302 & 1944.5 & 332.03 & 136 & 1520 & 1885 & 2255 & 1891.92 & 306.12 \\
\hline 35 & 90 & 1550 & 1950 & 2301 & 1933.89 & 301.72 & 178 & 1667 & 2025 & 2560 & 2060.86 & 344.94 \\
\hline 36 & 134 & 1550 & 2250 & 2585 & 2143.02 & 416.99 & 236 & 1645 & 2200 & 2570 & 2164.37 & 391.02 \\
\hline 37 & 136 & 1775 & 2240 & 2790 & 2248.53 & 430.99 & 322 & 1840 & 2350 & 2800 & 2340.81 & 384.96 \\
\hline 38 & 146 & 1895 & 2400 & 2895 & 2419.79 & 397.78 & 276 & 1985 & 2450 & 3040 & 2469.31 & 409.96 \\
\hline 39 & 82 & 1830 & 2350 & 3000 & 2349.88 & 419.67 & 192 & 1825 & 2500 & 3094 & 2485.16 & 470.86 \\
\hline 40 & 42 & 1924 & 2300 & 2886 & 2364.52 & 423.32 & 44 & 2109 & 2565 & 3024 & 2576.82 & 407.95 \\
\hline \multirow[t]{2}{*}{41} & 16 & 1395 & 1960 & 2650 & 2013.75 & 553.98 & 16 & 1925 & 2470 & 2895 & 2410 & 429.33 \\
\hline & & & & & & & 6 & 1960 & 2850 & 3030 & 2613.33 & 524.96 \\
\hline
\end{tabular}


Table 2 Smoothed birthweight (g) centiles by gestational age (weeks) for twins according to chorionic placentation

\begin{tabular}{|c|c|c|c|c|c|c|c|c|c|c|c|c|c|c|c|c|}
\hline \multirow[b]{2}{*}{$\mathrm{GA}$} & \multirow[b]{2}{*}{$\mathrm{N}$} & \multicolumn{7}{|c|}{ Monochorionic } & \multirow[b]{2}{*}{$\mathrm{N}$} & \multicolumn{7}{|c|}{ Dichorionic } \\
\hline & & P5 & P10 & P25 & P50 & P75 & P90 & P95 & & P5 & P10 & P25 & P50 & P75 & P90 & P95 \\
\hline 24 & 4 & 435 & 478 & 550 & 627 & 702 & 768 & 807 & 2 & 337 & 391 & 461 & 524 & 587 & 657 & 713 \\
\hline 25 & 8 & 503 & 553 & 636 & 725 & 812 & 889 & 934 & 2 & 426 & 490 & 574 & 652 & 729 & 813 & 877 \\
\hline 26 & 8 & 570 & 628 & 721 & 823 & 921 & 1008 & 1059 & 4 & 516 & 589 & 687 & 779 & 870 & 967 & 1040 \\
\hline 27 & 2 & 637 & 701 & 806 & 919 & 1029 & 1126 & 1183 & 12 & 610 & 692 & 804 & 910 & 1015 & 1125 & 1205 \\
\hline 28 & 6 & 707 & 778 & 894 & 1019 & 1141 & 1249 & 1312 & 12 & 709 & 799 & 924 & 1045 & 1165 & 1288 & 1376 \\
\hline 29 & 26 & 782 & 861 & 990 & 1129 & 1264 & 1383 & 1453 & 16 & 810 & 908 & 1047 & 1184 & 1319 & 1455 & 1551 \\
\hline 30 & 18 & 873 & 961 & 1104 & 1259 & 1409 & 1542 & 1621 & 26 & 914 & 1020 & 1173 & 1324 & 1475 & 1624 & 1728 \\
\hline 31 & 18 & 974 & 1073 & 1233 & 1405 & 1574 & 1722 & 1810 & 50 & 1020 & 1134 & 1301 & 1468 & 1633 & 1796 & 1907 \\
\hline 32 & 54 & 1081 & 1190 & 1367 & 1559 & 1746 & 1911 & 2008 & 80 & 1128 & 1250 & 1431 & 1613 & 1794 & 1971 & 2089 \\
\hline 33 & 54 & 1187 & 1307 & 1502 & 1712 & 1917 & 2098 & 2205 & 84 & 1238 & 1368 & 1563 & 1761 & 1957 & 2148 & 2274 \\
\hline 34 & 70 & 1293 & 1424 & 1636 & 1865 & 2089 & 2286 & 2402 & 136 & 1347 & 1485 & 1693 & 1907 & 2119 & 2323 & 2457 \\
\hline 35 & 90 & 1393 & 1533 & 1762 & 2009 & 2250 & 2462 & 2587 & 178 & 1454 & 1600 & 1821 & 2050 & 2277 & 2494 & 2635 \\
\hline 36 & 134 & 1489 & 1639 & 1883 & 2147 & 2404 & 2631 & 2765 & 236 & 1557 & 1709 & 1943 & 2187 & 2428 & 2657 & 2805 \\
\hline 37 & 136 & 1569 & 1727 & 1985 & 2263 & 2535 & 2774 & 2915 & 322 & 1653 & 1812 & 2057 & 2314 & 2569 & 2809 & 2963 \\
\hline 38 & 146 & 1624 & 1788 & 2055 & 2343 & 2624 & 2872 & 3018 & 276 & 1739 & 1904 & 2160 & 2428 & 2695 & 2946 & 3105 \\
\hline 39 & 82 & 1647 & 1815 & 2087 & 2381 & 2666 & 2919 & 3069 & 192 & 1817 & 1987 & 2251 & 2531 & 2808 & 3068 & 3232 \\
\hline 40 & 42 & 1646 & 1819 & 2096 & 2391 & 2680 & 2937 & 3090 & 44 & 1890 & 2064 & 2337 & 2626 & 2913 & 3181 & 3349 \\
\hline 41 & 16 & 1613 & 1801 & 2091 & 2391 & 2684 & 2952 & 3119 & 16 & 1960 & 2138 & 2419 & 2718 & 3014 & 3290 & 3462 \\
\hline 42 & 0 & & & & & & & & 6 & 2028 & 2210 & 2499 & 2807 & 3113 & 3396 & 3573 \\
\hline
\end{tabular}

P5 5th centile, $P 1010$ th centile, $P 25$ 25th centile, $P 50$ 50th centile, $P 75$ 75th centile, $P 9090$ th centile, nd P95 95th centile

based twin registries. The new birth weight curves may provide useful evidence for better understanding the birth weight of twins born in South India. For instance, it could serve as a useful tool for clinicians to evaluate and assess the birth weight of newborn twins. Additionally, this new centile curves should be a useful for epidemiologic research on twins related to determination of geographic differences, temporal trends and etiologic determinants of distribution of birth weight.

One of some limitations of this study is that the data were drawn from a tertiary care hospital, and hence it may restrict the generalizability of our results. However, given that twin pregnancies are considered as high-risk and often referred to tertiary care hospitals, the problems related to generalizability might be less likely. Another limitation is the measurement of gestational age using dates of last menstrual period, which suffers from recall bias. We believe our estimates are likely to be improved with the use of early ultrasound to correct estimates of gestational age. Also, data on birthweight and placental chorionicity captured during the course of routine clinical care may not be as precise as measurements under more controlled research settings. Thus, for example, we were not able to ascertain the extent of intra or inter observer variability. Additionally, the number of infants in extreme gestational ages was not sufficiently larger to enable accurate estimation of centiles. Further, in our study, the inclusion criteria resulted in a more general reference for birth weight, describing the variation in birth weight within a reference population and did not delineate variation that can be considered 'ideal' or of 'desirable targets'. Despite these limitations, our study will add to the existing scanty literature on birth weight distributions for twin births and will provide basis for future epidemiological studies on twins from this region.

\section{Conclusion}

The use of population specific birth weight centile curves will better aid both the clinician and researcher in the assessment of the birth weight of twins. Further, we recommend that assessment in twins consider placental chorionicity. The charts will provide a benchmark to examine the birth weight of twins in relation to other twins born of same gestational age, and would serve as a baseline for future epidemiological research studies. Future work will be to assess whether the infants identified in this way are those with high risk for poor perinatal outcomes, such as stillbirth and neonatal death.

\section{Abbreviation}

GAMLSS: generalized additive models for location scale and shape.

Competing interests

The authors declare that they have no competing interests 


\section{Authors' contributions}

PP performed the statistical analysis, designed the figures and drafted the manuscript. BA conceived the study, oversaw the project, provided the statistical advice and helped critically revise the manuscript. JM, SG, AR, RJ, AK and MM contributed to the interpretation of data and helped to revise the manuscript. All authors reviewed and approved the final manuscript.

\section{Acknowledgements}

We acknowledge Nithya Jeyaseeli and Regina Varghese for their assistance with the data collection.

\section{Author details}

${ }^{1}$ Departments of Biostatistics, Christian Medical College, Vellore 632002 India. ${ }^{2}$ Obstetrics and Gynaecology, Christian Medical College, Vellore 632 002, India. ${ }^{3}$ Neonatology, Christian Medical College, Vellore 632 002, India. ${ }^{4}$ Making Pregnancy Safer Department, World Health Organization, Geneva, Switzerland.

\section{Received: 19 May 2014 Accepted: 16 March 2016}

\section{Published online: 24 March 2016}

\section{References}

1. Smits J, Monden C. Twinning across the Developing World. PLoS ONE. 2011;6: e25239.

2. Cheung YB, Yip P, Karlberg J. Mortality of Twins and Singletons by Gestational Age: A Varying-Coefficient Approach. Am J Epidemiol. 2000;152:1107-16.

3. Garite TJ, Clark RH, Elliott JP, Thorp JA, the Pediatrix/Obstetrix Perinatal Research Group. Twins and triplets: The effect of plurality and growth on neonatal outcome compared with singleton infants. Am J Obstet Gynecol. 2004;191:700-7.

4. Buckler J, Green M. Birth weight and head circumference standards for English twins. Arch Dis Child. 1994;71:516-21.

5. Kato N. Reference birthweight range for multiple birth neonates in Japan. BMC Pregnancy Childbirth. 2004;4:2.

6. Min SJ, Luke B, Gillespie B, Min L, Newman RB, Mauldin JG, Witter FR, Salman FA, O'Sullivan MJ. Birth weight references for twins. Am J Obstet Gynecol. 2000;182:1250-7.

7. Ooki S. Effect of Maternal Age and Fertility Treatment on the Increase in Multiple Births in Japan: Vital Statistics, 1974-2009. J Epidemiol. 2011:21:507-11.

8. Alexander AM, George K, Muliyil J, Bose A, Prasad JH. Birthweight centile charts from rural community-based data from southern India. Indian Pediatr. 2013:50:1020-4.

9. Kandraju H, Agrawal S, Geetha K, Sujatha L, Subramanian S, Murki S. Gestational age-specific centile charts for anthropometry at birth for South Indian infants. Indian Pediatr. 2012;49:199-202.

10. Mathai M, Jacob S, Karthikeyan N. Birthweight standards for south Indian babies. Indian Pediatr. 1996;33:203-10.

11. Joseph K, Fahey J, Platt RW, Liston RM, Lee SK, Sauve R, Liu S, Allen AC, Kramer MS. An outcome-based approach for the creation of fetal growth standards: do singletons and twins need separate standards? Am J Epidemiol. 2009;169:616.

12. Gielen M, Lindsey PJ, Derom C, Loos RJF, Souren NY, Paulussen ADC, Zeegers MP, Derom R, Vlietinck R, Nijhuis JG: Twin-specific intrauterine "growth" charts based on cross-sectional birthweight data. Twin Res Hum Genet. 2008:11:224-35

13. Sankilampi U, Hannila M-L, Saari A, Gissler M, Dunkel L. New population-based references for birth weight, length, and head circumference in singletons and twins from 23 to 43 gestation weeks. Ann Med. 2013:45:446-54

14. Dollberg S, Haklai Z, Mimouni FB, Gorfein I, Gordon E-S. Birth weight standards in the live-born population in Israel. Isr Med Assoc J. 2005;7:311-4.

15. Shinwell ES. Birth weight standards: how Israeli singleton and twin fetuses grow. Isr Med Assoc J. 2005;7:338.

16. Baghdadi S, Gee H, Whittle MJ, Khan KS. Twin pregnancy outcome and chorionicity. Acta Obstet Gynecol Scand. 2003;82:18-21.

17. Sherer DM. Adverse Perinatal Outcome of Twin Pregnancies According to Chorionicity: Review of the Literature. Am J Perinatol. 2001;18:023-38

18. Ananth CV, Vintzileos AM, Shen-Schwarz S, Smulian JC, Lai YL. Standards of birth weight in twin gestations stratified by placental chorionicity. Obstet Gynecol. 1998;91:917-24
19. Rigby R, Stasinopoulos D. The GAMLSS project: a flexible approach to statistical modelling. In: New Trends in Statistical Modelling: Proceedings of the 16th International Workshop on Statistical Modelling. 2001. p. 337-45.

20. Stasinopoulos DM, Rigby RA. Generalized additive models for location scale and shape (GAMLSS) in R. J Stat Softw. 2007:23:1-46.

\section{Submit your next manuscript to BioMed Central and we will help you at every step:}

- We accept pre-submission inquiries

- Our selector tool helps you to find the most relevant journal

- We provide round the clock customer support

- Convenient online submission

- Thorough peer review

- Inclusion in PubMed and all major indexing services

- Maximum visibility for your research

Submit your manuscript at www.biomedcentral.com/submit 